
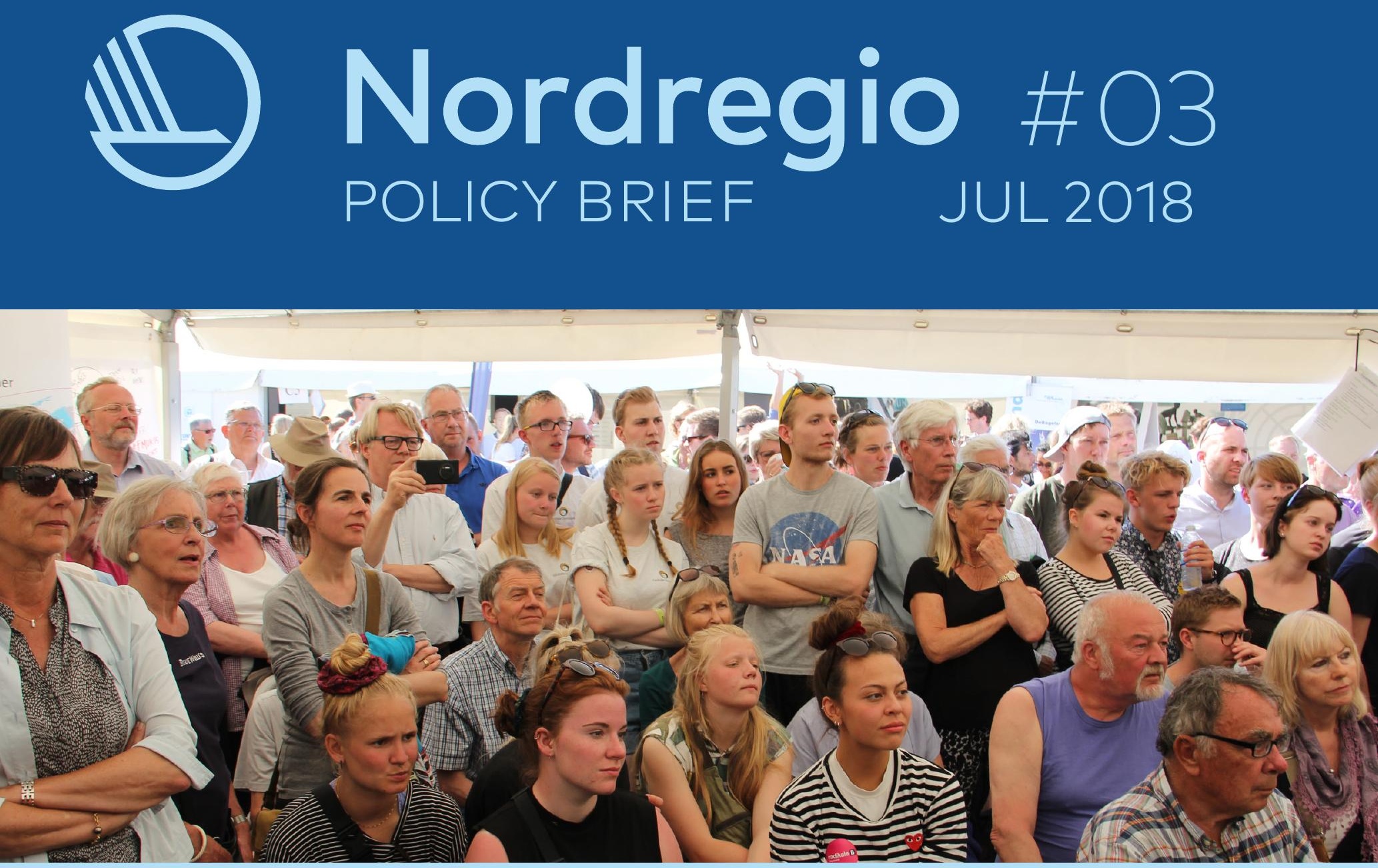

\title{
Stege, trappa eller kub - hur analysera dialoger i stadsplanering?
}

Att medborgarna ska ha möjlighet att påverka sin stads utveckling är ett starkt demokratiideal idag. Sedan 1987 har kommuner och landsting en skyldighet enligt lag att samråda med invånare i vissa fall inom plan- och byggfrågor och 2015 tillämpade över 80 procent av Sveriges kommuner någon form av medborgardialog. Men vad finns det för verktyg för att undersöka vilken typ av inflytande kommunerna möjliggör med det inbjudna deltagandet?

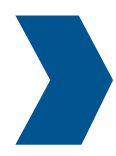

Det finns en otydlighet i två av de mest inflytelserika dialogverktygen; delaktighetsstegen och delaktighetstrappan. 'Delaktighet' beståravmångakomponenter, till exempel;vem tillåts ha inflytande? På vilket sätt? Hur är inflytandet egentligen kopplat till beslut över en sakfråga? Denna komplexitet framgår dock inte av stegen och trappan. En del kritiker menar att verktygen är problematiska då de är normativa i sin utformning och visar att större maktdelning till medborgarna alltid är bättre (Malm, G., Jarnhammar, M. och Elmén, S. 2018). Om vi vänder oss till ett annat verktyg; demokratikuben, så finner vi ett redskap som inte förespråkar en viss nivå av inflytande. Demokratikuben delar in delaktighet i fler dimensioner och därmed möjliggörs också en mer precis analys av det inbjudna deltagandet. 


\section{FAKTABOX}

Demokratiutredningen från 2016 uttrycker att medborgardialog i regel är ett tillfälle som bjuds in till av den offentliga sektorn där offentliga tjänstepersoner och politiker möter invånare, intressegrupper eller andra aktörer med syfte att dessa ska få framföra synpunkter eller delta i utformandet av beslut. 'Samråd' används för att beteckna att kommuner stämmer av eller inhämtar synpunkter från vissa grupper av aktörer eller invånare.

(SOU 2016:5)

Samrådet, det vill säga den lagstadgade möjligheten för bland annat medborgarna att få granska och ge synpunkter på planeringsförslag, tillkom som en reaktion på bristen på just medborgarperspektiv i planeringen under efterkrigstiden. Ett vanligt nutida argument för medborgardialog är att denna kan kompensera för det minskande partipolitiska engagemanget, något som innebär att färre människor har reellt inflytande över politiken. En viktig invändning är dock att det ofta är de som redan är mest politiskt aktiva som tar plats i samråds- och dialogmöten, vanligen välutbildade och resursstarka personer, ofta män. Därmed riskerar syftet med deltagande processer som en inkluderande praktik att motverkas.

De senaste åren har kommuner experimenterat med olika metoder att föra dialog i stadsbyggnadsfrågor och det finns en stor spännvidd mellan vilken form av inflytande som erbjuds och möjliggörs. Historiskt och internationellt har 'deltagande' i styrningsprocesser använts både för att legitimera de policyinriktningar som myndigheter själva föredrar och för att utöva makt över befolkningar. 'Dialog' är ett begrepp som kan förstås väldigt olika av både avsändare och mottagare. Det finns alltså starka argument för att vi behöver förstå mer om det som görs i namn av "dialog" och "deltagande". Vilka deltar? Hur deltar de, och hur används deras deltagande i beslutsprocesser?

\section{VERKTYG SOM HJÄLPER OSS FÖRSTÅ DIALOGERNA}

Två modeller och metaforer för att analysera och designa medborgardialoger har fått stort genomslag i Sverige; Arnsteins stege och SKL:s delaktighetstrappa. Dessa visar på olika nivåer av inflytande som invånarna kan ha i en dialog.

Vi vill här introducera en tredje modell demokratikuben - som separerar inflytande i två dimensioner där en handlar om hur kommunikationen går till och den andra handlar om vilken koppling dialogen har till beslut. Den tillför också en dimension om vem som deltar. När vi har tillämpat demokratikuben för att analysera hur medborgardialoger har förts i tolv svenska kommuner mellan 2005-2015, ser vi att den vanligaste kopplingen till beslut är att dialogaktiviteten fungerar som ett sätt för tjänstepersoner att konsultera invånarna. Vi ser också att det allra vanligaste sättet att bjuda in till dialog är via öppna inbjudningar där deltagarna så att säga "rekryterar sig själva". De väljer frivilligt att gå på ett möte eller gå in i lokalen i köpcentrumet och se på aktuella planer. För att nå ut bredare, och inte endast till de som rekryterar sig själva, är det också vanligt att man arbetar uppsökande med riktad rekrytering t.ex. genom att aktivt besöka och rekrytera deltagare från skolor, vårdcentraler, intresseorganisationer $\mathrm{mm}$. På så sätt vill man nå särskilda grupper, ibland specifikt grupper som man ett har ett svagt politiskt inflytande.

\section{ARNSTEINS STEGE - ETT KRITISKT MEN KONSTRUKTIVT VERKTYG}

1969 introducerade Sherry Arnstein delaktighetsstegen. Den är ett kritiskt verktyg som kan åskådliggöra om dialog används för att det ska se ut som att invånare blir involverade, men utan att det faktiskt finns chans att påverka några beslut. Steg ett och två beskriver olika former av icke-deltagande där dialogen används till att påverka deltagarnas uppfattningar snarare än tvärt om, eller för att flytta fokus från de verkligt brännande frågorna. Steg tre till fem betecknar olika former av vad Arnstein kallar symboliskt deltagande. Här bjuds invånare in att få information och att göra sina röster hörda, men de saknar möjligheter att kontrollera att deras synpunkter blir beaktade. Beslutsfattarna behåller makten över besluten. Steg

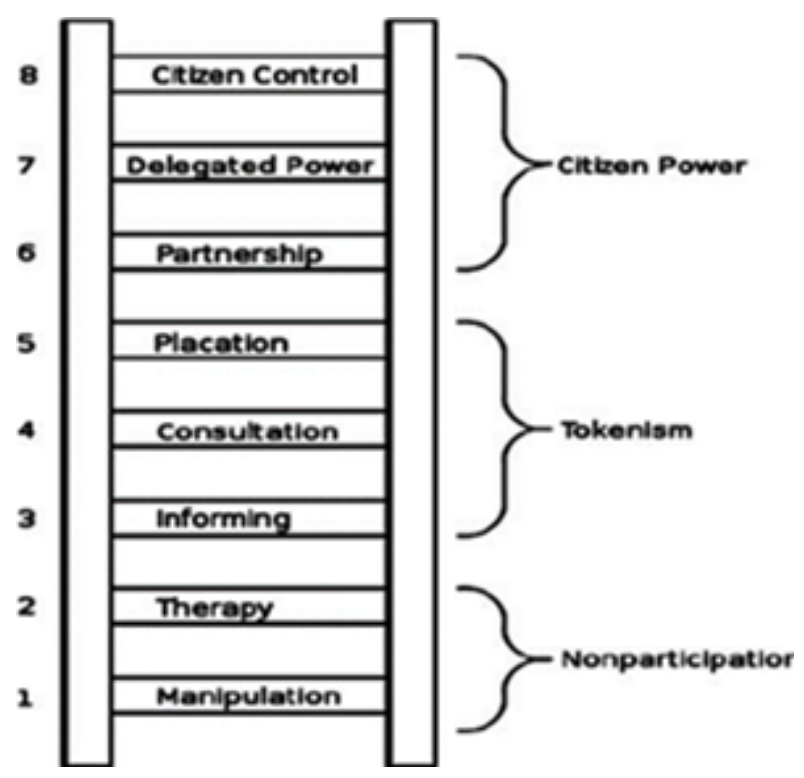

Figur 1: Sherry Arnsteins stege (Arnstein, 1969) 
sex till åtta beskriver olika former av medborgarmakt. Här omfördelas makt genom att invånarna får en majoritet i styrelser och kommittéer, eller i form av råd som har veto. På så sätt visar stegen också på att makt kan omfördelas till de boende och att dessa kan få en betydande roll i den lokala utvecklingen.

Sherry Arnstein arbetade i Washington DC på US Department of Housing, Education and Welfare i 1960-talets USA. Hennes figur var tänkt som ett verktyg för kritisk analys av medborgardeltagande. Få arrangörer av medborgardialoger skulle erkänna att de vill hamna på steget "manipulation". Med stegen synliggjorde hon hur "have-nots", det vill säga de resurssvaga, blev lurade i samarbetet med beslutsfattare, men också hur de ibland hade makt över beslut som påverkade deras vardag. "Havenots" betecknade socioekonomiskt missgynnade etniska minoriteter, i synnerhet den afroamerikanska befolkningen, i ett samhälle som efter slaveriet fortfarande präglades av rasism, segregation och förtryck. Det är således en verklighet som skiljer sig mycket från den svenska och nordiska nutiden. I Sverige, och Norden, tillämpas medborgardialog i områden med väldigt olika socioekonomisk karaktär, och även i resursstarka områden.
(6) Initiativtagaren till medborgardialog måste från början

vara tydlig med vilken grad av delaktighet som planeras samt syftet med medborgardialogen."

\section{Exempel på hur delaktighetstrappan kommenteras i kommunalt policydokument}

\section{DELAKTIGHETSTRAPPAN - MER ANPASSAD TILL DEN SVENSKA KONTEXTEN?}

Den så kallade "delaktighetstrappan" har tagits fram av Sveriges Kommuner och Landsting ( $S K L$ ) och är inspirerad av Arnsteins stege, men bör förstås mer som ett verktyg för tillämpning än för kritisk analys. Den är

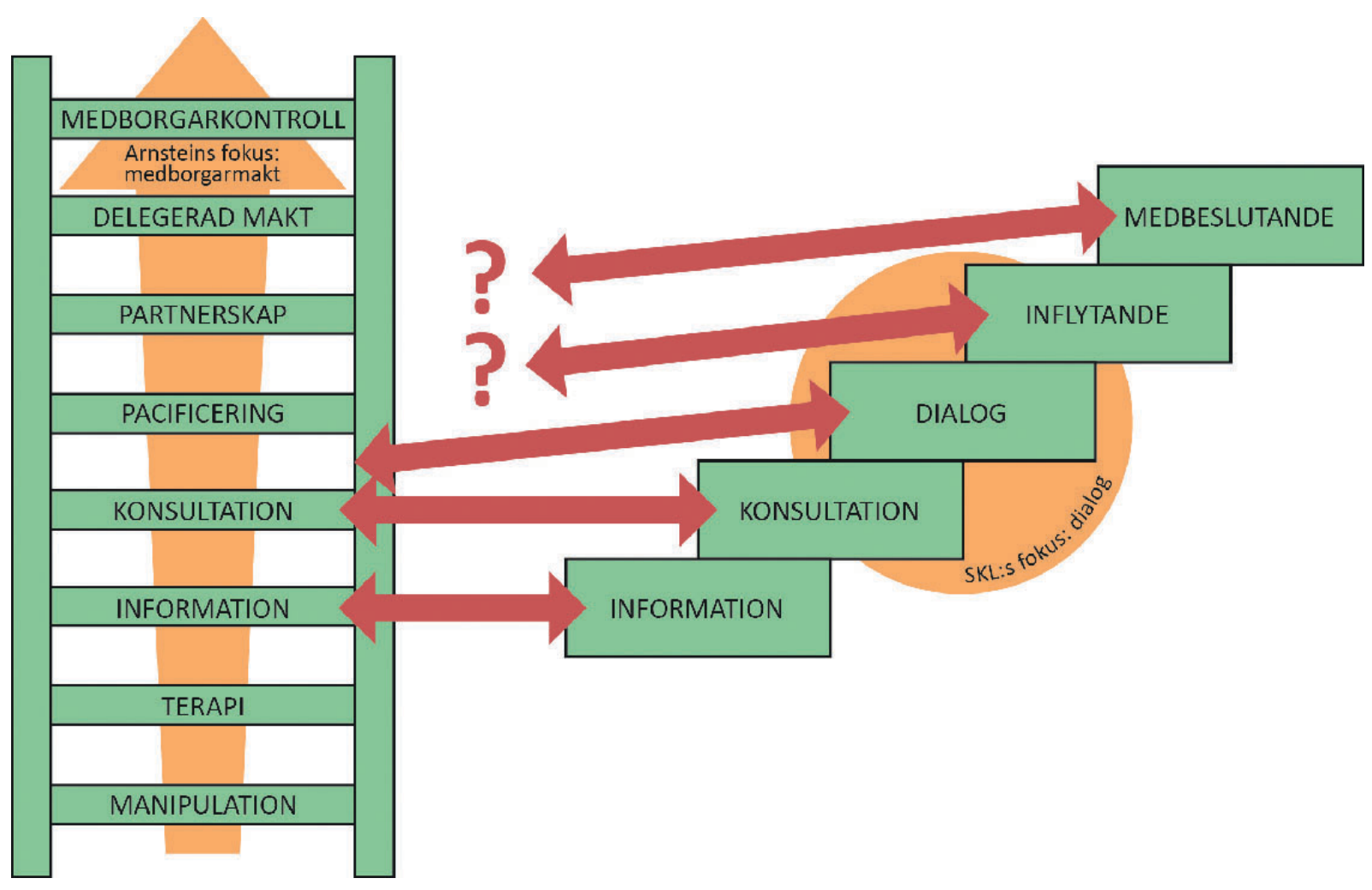

Figur 2: Jämförelse av Arnsteins stege ochSKL:s delaktighetstrappa (SKL, 2011). Källa: mellanplats.se/ Pål Castell 


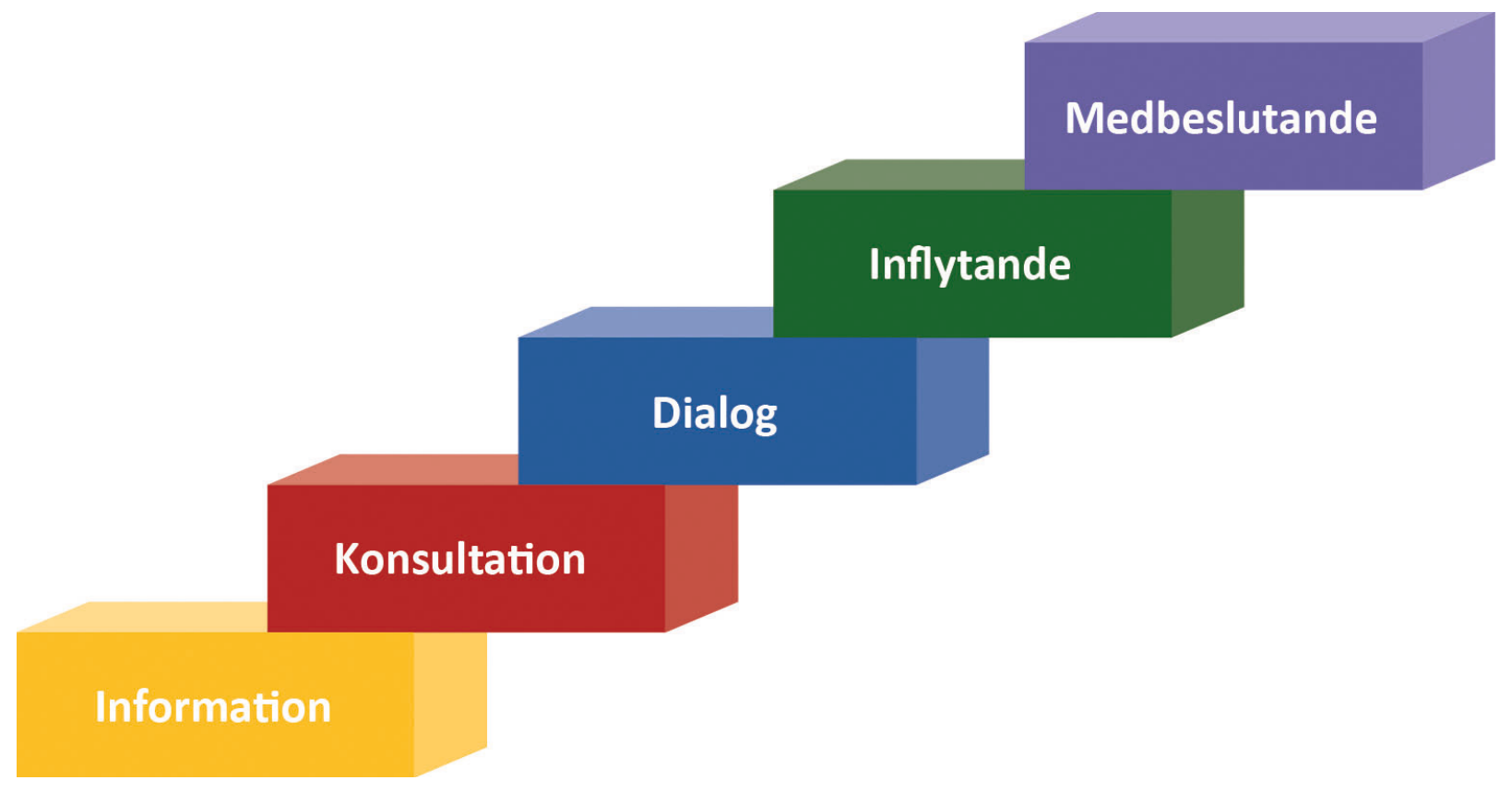

Figur 3: SKL:s delaktighetstrappa (SKL, 2011). Källa: mellanplats.se/ Pål Castell

vida spridd till svenska kommuner genom SKL:s arbete med demokratifrågor i den kommunala styrningen. I kommunala policydokument används den ofta som ett stöd för att förklara för kommunens medarbetare vad en medborgardialog är. Den nyttjas också ofta av tjänstepersoner i dialogprocesser för att visa för deltagarna vilken nivå av inflytande de kan förvänta sig.

Stegen är inriktad på omfördelning av makt från de resursstarka till de som inte har. Medan Arnstein menade att ju mer makt som omfördelas till "the havenots" desto bättre, så är SKL:s trappa en bild av olika strategier att välja bland där det högsta steget på Arnsteins stege - medborgarkontroll - inte finns med.

I SKL:s modell har alltså de steg som innebär mest omfördelning av makt till medborgarna försvunnit, liksom de lägsta stegen som betonar icke-deltagande. Designen med den progressiva riktningen uppåt mot höger visar ändå på en strävan mot medbes/utande, dvs så mycket medborgarinflytande som möjligt.

Nedan beskrivs de fem stegen i delaktighetstrappan lite mer ingående (förenklat från SKL (2011)):

Information: för att kunna vara delaktig behöver man lättillgänglig information

Konsultation: medborgarnas delger sina synpunkter om ett specifikt ämne

Dialog: medborgarna för dialog med andra om olika frågor som rör samhällets utveckling. Syftet är att deras intressen, kunskap och önskemål beaktas i den fortsatta politiska processen
Inflytande: medborgarna deltar under en längre period från identifiering av behov till förslag till genomförande som bildar underlag till politiska beslut

Medbeslutande: den representativt valda församlingen kan delegera ansvar till nämnd eller styrelse där delegaterna är valda som enskilda personer.

\section{DEMOKRATIKUBEN SYNLIGGÖR FLER DIMENSIONER}

Nu lägger vi en kub till metaforiken. Archon Fungs demokratikub kan ses som både en analysram för att förstå dialogens olika dimensioner, och som ett verktyg för en praktiker. Den visar på olika möjligheter att utforma offentlig styrning och framhåller rekrytering av deltagare, kommunikation och beslutsfattande som tre bärande dimensioner som hjälper oss att förstå vad det är som sker i deltagandeprocesser.

Den första dimensionen handlar om vem som deltar och hur deltagarna bjuds in. Det är viktigt att ta reda på om deltagarna representerar den relevanta befolkningen och om de representerar de intressen som finns i frågan, men också huruvida de har tillräcklig information och kunskap för att ta beslut. En till viktig fråga är huruvida deltagarna är ansvarsskyldiga gentemot de som inte deltar. Den andra dimensionen handlar om vad deltagarna får göra och hur de interagerar med kommunen. Kuben har sex olika alternativ för detta. Den tredje dimensionen handlar om vilket inflytande deltagarna har över offentliga beslut. Här sträcker sig alternativen från att man 
deltar för att skaffa sig kunskap, till att deltagarna har direkt inflytande över beslut.

Kuben ger en utökad begreppsapparat för vad som sker i dialogerna. Den lyfter fram i vilken roll den som deltar gör det (som föreningsrepresentant, slumpvis utvald, expert $\mathrm{mm}$ ) och synliggör därmed den viktiga frågan om vem som deltar - vem ges tillgång till dessa kompletterande demokratiska forum och hur? Stegen utgår helt ifrån invånarnas deltagande eller icke-deltagande, medan kuben även kan fördjupa förståelsen för "traditionellt" beslutsfattande eftersom både experter och politiker kan placeras in i den. Som påpekades i inledningen är ett vanligt argument för att tillämpa deltagandeprocesser att öka inflytandet för grupper i samhället som har lågt politiskt deltagande. Därför är påminnelsen om denna dimension ett välkommet inslag i analysverktyg för deltagandeprocesser. Om man använder kuben för att analysera flertalet aktiviteter inom en dialogprocess, så kan man se hur olika typer av deltagare ges olika möjligheter till kommunikation och beslutsfattande i de olika aktiviteterna.

Eftersom kuben inte innehåller en inneboende hierarki där maktöverföring till invånarna är det som sätts högst, så kan den tillämpas som analysram i den svenska och nordiska kontexten där dialogpraktiken inte har kommit att utmana den representativa demokratin.
(6)

Resultatet av workshopen kommer att vara ett viktigt kunskapsunderlag i

utarbetandet av programmet. Det finns dock ingen garanti att de idéer som kommer fram kommer att genomföras då det finns många aspekter att ta hänsyn till i stadsplaneringen."

Ur en sammanställning från en workshop som gjorts inför framtagandet av ett planprogram.

\section{SVENSKA STADSBYGGNADSDIALOGER ÄR MEDBORGARNA RÅDGIVARE}

I syfte att förstå mer om hur dialoger går till i svensk stadsplanering idag, har vi tillämpat Fungs amerikanska kub i en kartläggning av medborgardialogaktiviteter

\begin{tabular}{|l|l|l|}
\hline Vem deltar? & Deltagarna får... & Deltagarna kan... \\
\hline Media/offentlig sfär & Ta emot information & Lära sig \\
\hline "Alla"/De som vill & Uttrycka sin åsikt & $\begin{array}{l}\text { Påverka genom den } \\
\text { allmänna opinionen }\end{array}$ \\
\hline $\begin{array}{l}\text { De som har blivit upp- } \\
\text { sökta av kommunen }\end{array}$ & $\begin{array}{l}\text { Utveckla sin kunskap och ge } \\
\text { förslag }\end{array}$ & Ge ro̊d och bli konsulterad \\
\hline $\begin{array}{l}\text { De som valts ut genom } \\
\text { slumpmässigt urval }\end{array}$ & Deliberera & $\begin{array}{l}\text { Samstyra (göra planer stra- } \\
\text { tegier) }\end{array}$ \\
\hline Föreningsaktiva & Förhandla & Besluta \\
\hline Privata aktörer & Tillämpa sin expertis & \\
\hline
\end{tabular}

Figur 4: Figuren är en förenklad och anpassad version av demokratikuben (Fung 2006; 2015) 


\title{
LÄRDOMAR
}

\section{FÖRDELAR OCH NACKDELAR MED DE OLIKA VERKTYGEN}

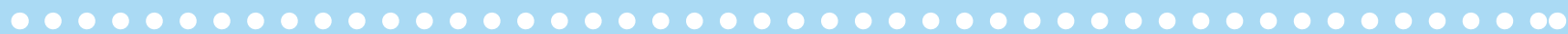

Det är viktigt att poängtera att ingen av de tre modellerna är utvecklad särskilt för att tillämpas just för medborgardialoger i fysiska planprocesser. Men, alla tre har kvaliteter som kan hjälpa både dialogaktörer och forskare att understryka eller få syn på olika aspekter av medborgardialoger.

Kuben kan användas för att förstå styrning och beslutsfattande i vidare mening, och kan alltså visa vilken plats medborgardialoger får i relation till andra beslutsprocesser där medborgare inte bjuds in

Kuben tydliggör att en deltagandeprocess har flera dimensioner och att det är viktigt att synliggöra vem som deltar

Kuben förhåller sig direkt till den representativa demokratin

Stegen är normativ - det är bäst högst upp
Stegen och trappan kan vara användbara för den som vill förstå eller åskådliggöra dialogprocesser separerat från planprocessen

Stegen pekar ut olika nivåer av medborgarmakt, och utmanar därmed den representativa demokratin

Trappan är normativ - alla steg på den är bra

Trappan är enkel att kommunicera även till en publik som inte är expert på dialog i tolv svenska kommuner under 2000-talet. När det kommer till hur man bjuder in till dialog, är det vanligast att "alla" bjuds in att delta, vilket betyder att deltagarna i princip rekryterar sig själva efter att ha fått information om dialogtillfället. Det förekommer också att de uppsöks genom riktad rekrytering. I en strävan att nå andra än de som traditionellt har högljudda åsikter i lokal stadsutveckling så förekommer olika typer av "riktad rekrytering" av exempelvis barn och tonåringar i skolor, förskolor eller på ungdomsgårdar, men också av småbarnsföräldrar och kvinnor via $t$ ex vårdcentraler och öppna förskolor. Att direkt rikta sig till föreningsaktiva är också ett vanligt sätt att bjuda in specifika grupper till dialog. Kommunerna riktar sig således direkt till de grupper som är berörda, men arbetar också aktivt för att nå de som vanligen inte deltar.

En vanlig uppgift som dialogdeltagarna får är att uttrycka sin åsikt. Detta sker till exempel genom att deltagarna får sätta små klisterlappar på ett ortofoto över planområdet med omnejd för att markera var de bor och hur de upplever området - exempelvis röda prickar för platser där de tycker det finns otrygghet eller problem, gröna prickar på platser de tycker om och vill ha kvar som de är. Prickarna kompletteras med skriftliga synpunkter. Andra sätt att få uttrycka sin åsikt är enkäter eller dialogmöten där deltagarna direkt kan delge sina synpunkter till kommunala representanter.

Att utveckla sin kunskap och ge förslag betyder att deltagarna får möjlighet att uttrycka hur de upplever en plats och hur de skulle vilja förändra den, men att de dessutom får information som ger dem vidare kunskap om området och planeringsförutsättningarna och att det finns möjlighet att diskutera och utveckla sina tankar om platsen tillsammans med andra. Här ges utrymme till mer initierade diskussioner. Flertalet dialogaktiviteter kan klassas som sådana. Ofta handlar det om att deltagarna får presentationer om området och planeringsförutsättningarna och att diskussioner sker i mindre grupper. Emellanåt rekryteras deltagare till fokusgrupper som möts mer än en gång.

Att ge råd och bli konsulterad är den absolut vanligast förekommande relationen mellan dialogaktiviteterna och beslutsfattandet, om man här betraktar beslutsfattandet som att utforma planen. Detta innebär att dialogaktiviteterna används för att samla in information och underlag om platsen och om vad människor vill med den. Planerarna är lyhörda för synpunkter, men de förbehåller sig rätten att bedöma vad av synpunkterna som kan tillmötesgås i utformningen av planen. 


\section{OM FORSKNINGSPROJEKTET}

Projektet Medborgardeltagandets effekter: en kartläggning och utveckling av den kommunikativa planeringens omfattning, former och resultat undersöker inbjudet medborgardeltagande i stadsplaneringsprocesser i tolv svenska kommuner mellan år 2000 och 2015. Deltagare i projektet är Förvaltningshögskolan Göteborgs universitet, Kungliga Tekniska Högskolan (KTH), Nordregio samt kommunerna Stockholm, Nacka, Botkyrka, Upplands Väsby, Göteborg, Alingsås, Tjörn, Lerum, Malmö, Helsingborg, Lund och Landskrona. Associerade partners är: Trafikverket, Mistra Urban Futures, Boverket och SKL. Projektet finansieras av FORMAS, Mistra Urban Futures och Trafikverket. Projektet avslutas under 2019.

\section{Källor och lästips}

Arnstein R, S. (1969) A Ladder of Citizen Participation Journal of the American Institute of Planners 35:4, 216-224 DOI: 10.1080/01944366908977225

Cars, G. (2015) Medborgardialog - ett verktyg för att stärka demokratin i samhällsplaneringen? Lindholm, T., Oliveira e Costa, S., Wiberg, S. (2015) Medborgardialog - demokrati eller dekoration? Tolv röster om dialogens problem och potential $i$ samhällsplaneringen Arkus \#72 Ljungbergs tryckeri, Klippan. ISBN 978-91-980422-3-8

Castell, P. (2013) Stegen och trappan - olika syn på deltagande i Stenberg, J. et al. (2013) Framtiden är redan här Hur invånare kan bli medskapare i stadens utveckling Göteborg, Chalmers tekniska högskola, ISBN 978-91-980300-7-5

Cornwall, A. (2008) Unpacking 'Participation': models, meanings and practices Community Development Journal Vol 43:3 s. 269-283 doi: 10.1093/ cdj/bsn010

Fung, A. (2006) Varieties of participation in complex governance Public Administration Review December 2006 Special Issue

Fung, A. (2015) Putting the public back in to governance: The challenges of citizen participation and its future Public Administration Review 2015 DOI: 10.1111/puar.12361.

Göteborgs stad (2013) Sammanställning av workshop - program för Sahlgrenska och Medicinareberget, Stadsbyggnadskontoret.

Linköping kommun (2016) Riktlinjer för Medborgardialog i Linköpings kommun http://www.linkoping.se/contentassets/ d91c4b30b0ca422db0cb94b3fff6861f/riktlinjer-formedborgardialog-i-linkopings-kommun.pdf

Malm, G., Jarnhammar, M. och Elmén, S. (2018)

Tolv insikter för en socialt hållbar planering

Utgivare: Södertörnsmodellen, Idégruppen om medborgardialog \& social konsekvensbeskrivning

SKL (2011) Handbok i utvärdering av medborgardialog ISBN: 978-91-7164-715-3

SOU 2016:5 Låt fler forma framtiden! Betänkande av 2014 års Demokratiutredning - Delaktighet och jämlikt inflytande Statens offentliga utredningar Elanders Sverige AB, Stockholm 2016. ISBN 978-91-38-24401-2 ISSN 0375-250X

\section{Författare}

Sandra Oliveira e Costa sandra.oliveiracosta@nordregio.org

Moa Tunström moa.tunstrom@nordregio.org

\section{Övriga forskare i projektet}

Nazem Tahvilzadeh, KTH

Ilhan Kellecioglu, Nordregio

Stig Montin, Göteborgs universitet

\section{Kommunikation}

Johanna Feuk

johanna.feuk@nordregio.org

\section{Omslagsbild}

norden.org/Mette Højberg

Tinna Harling, Tjörns kommun

Botkytka kommun

ISSN 2001-3876

URL: doi.org/10.30689/PB2018:3.2001-3876

www.nordregio.org 